\title{
Uma maloca-museu para Feliciano Lana, o filho dos desenhos dos sonhos
}

Denilson Baniwa, 36 anos, nasceu em Mariuá, no Rio Negro, Amazonas. Sua trajetória como artista inicia-se a partir das referências culturais de seu povo já na infância. Na juventude, o artista inicia a sua trajetória na luta pelos direitos dos povos indígenas e transita pelo universo não-indígena apreendendo referenciais que fortaleceriam o palco dessa resistência. Denilson Baniwa é um artista antropófago, pois apropria-se de linguagens ocidentais para descolonizá-las em sua obra. 0 artista em sua trajetória contemporânea consolida-se como referência, rompendo paradigmas e abrindo caminhos ao protagonismo dos indígenas no território nacional. <denilsonbaniwa@gmail.com> ORCID: 0000-0003-1763-5830
Resumo Quando um mestre morre leva com ele uma infinidade de experiências e conhecimentos, foi assim que nos sentimos quando perdemos o Sr Feliciano Lana, indígena do povo Desana que o Covid-19 levou nesta crise de saúde mundial. $\mathrm{O}$ texto que compartilho aqui é uma reivindicação ao que o $\mathrm{Sr}$ Feliciano Lana representa aos artistas indígenas contemporâneos e também uma tentativa de levar sua memória para além das fronteiras índio-aldeia. É preciso compreender a produção de Lana como uma importante geografia no que podemos repensar a arte brasileira, ou arte originária. O legado que Lana nos deixa é um banco de dados, conhecimentos mágicos e cotidianos que conectam os mundos, que precisam ser estudados, preservados e compartilhados com todos, principalmente com aqueles que ainda irão nascer. Enquanto índio-artista eu preciso cuidar da memória para que ela esteja presente nos pensamentos vivos, pois entender o passado é cuidar para que o futuro seja uma boa experiência para os que virão. É preciso enquanto artista pensar sobre uma arte-pussanga e uma maloca-museu para ampliarmos o sentido da arte.

Palavras chave Arte Indígena, Arte Contemporânea, Legado, Memória. 


\title{
A maloca-museum for Feliciano Lana, the son of the drawings of dreams
}

\begin{abstract}
When a master dies he takes a multitude of experiences and knowledge with him, that's how we felt when we lost Mr. Feliciano Lana, an indigenous of the Desana people that Covid-19 took in this world health crisis. The text I share here is a claim to what Mr Feliciano Lana represents to contemporary indigenous artists and also an attempt to take his memory beyond the indian-village boundaries. It is necessary to understand Lana's production as an important geography in which we can rethink Brazilian art, or original art. The legacy that Lana leaves us is a database, magical and everyday knowledge that connect the worlds, which need to be studied, preserved and shared with everyone, especially those who are yet to be born. As an indian artist, I need to take care of memory so that it is present in living thoughts, because understanding the past is taking care to make the future a good experience for those who will come. It is necessary as an artist to think about an art-pussanga and a maloca-museum to expand the meaning of art.
\end{abstract}

Keywords Indigenous art, Contemporary art, Legacy, Memory.

\section{Una maloca-museo para Feliciano Lana, el hijo de los dibujos oníricos}

Resumen Cuando un maestro muere se lleva multitud de experiencias y conocimientos, así nos sentimos cuando perdimos al señor Feliciano Lana, un indígena del pueblo Desana que tomó Covid-19 en esta crisis de salud mundial. El texto que comparto aquí es un reclamo de lo que el Sr. Feliciano Lana representa para los artistas indígenas contemporáneos y también un intento de llevar su memoria más allá de los límites de las aldeas indígenas. Es necesario entender la producción de Lana como una geografía importante en la que podemos repensar el arte brasileño, o el arte original. El legado que nos deja Lana es una base de datos, conocimientos mágicos y cotidianos que conectan los mundos, que necesitan ser estudiados, preservados y compartidos con todos, especialmente con los que están por nacer. Como artista indio, necesito cuidar la memoria para que esté presente en los pensamientos vivos, porque comprender el pasado es cuidar que el futuro sea una buena experiencia para los que vendrán. Es necesario como artista pensar en un arte-pussanga y una maloca-museo para ampliar el significado del arte.

Palabras clave Arte indígena, Arte Contemporáneo, Legado, Memoria. 
Antes do tempo a escuridão dominava, tudo era um grande vazio sem memória. $O$ nada existia e era ele mesmo seu próprio pensamento. Houve um estalo no silêncio como de uma semente a germinar. E sentada num banco de quartzo, empunhando em uma das mãos uma cuia de ipa$\mathrm{du}^{1}$ e em outra uma forquilha para segurar o cigarro de tabaco, surgiu por sua própria vontade Yebá Buró, a Avó do Mundo, aquela que por si mesma quiser Ser, por isso a chamamos de a Não-Criada, pois ela mesma se fez em seu pensamento. Coberta com enfeites mágicos e brilhantes, sua presença era tão magnífica que o reflexo de seu brilho deu vida à escuridão e até onde alcançou aquela luz ficou conhecido como Utãboho Taribu, o Quarto de Quartzo Branco.

Ainda sentada e mirando o vazio da memória ela comeu ipadu, fumou tabaco e refletiu sobre o futuro do Cosmos e dos seres. Foi ela quem pensou como deveria ser o passado, presente e futuro. Que nada mais são, que toda a memória em gestação a partir daquele momento.

Esta é minha interpretação sobre uma das versões da Gênese que conheci através da família Lana, que em meados dos anos 80 resolveram que iriam registrar em símbolos gráficos ocidentais as suas memórias guardadas e aprendidas por seu povo desde quando Yebá Buró surgiu.

O livro-narrativa escrito pelo Sr. Firmiano Lana e Luiz Lana foi o primeiro registro do que eu poderia entender sobre a estética da arte indígena moderna. O Sr Feliciano Lana, sobrinho de Firmiano e primo de Luiz, deu continuidade ao legado de seus parentes, cada vez mais indo criando um estilo próprio e aumentando o repertório de narrativas visuais desana e por vezes criando suas próprias narrativas a partir de suas experiências diárias. 
O que só compreendo hoje é a importância dos Lana na criação de uma imagética inédita na cultura indígena brasileira. Assim como o cristianismo criou a imagem de seu Deus e o difundiu através da arte, assim a família Lana deu registro aos "deuses" da cosmogonia desana, que antes só sabíamos oralmente através dos pajés, que eram os únicos a conseguirem o trânsito livre pelos Mundos.

As tintas e pinceladas de Feliciano Lana me deram a experiência de saber como eram a Cobra-Canoa, Yebá Buró, Lago de Leite e as Malocas do Universo. A importância da energia criativa de Feliciano Lana é incalculável para o mundo inteiro, ainda mais para um artista indígena como eu sou. Antes dos Lana toda a oralidade era transformada em nossa imaginação, como será o Umukomahsü Boreka? Seria alto, baixo, magro, gordo, que expressão há em seu rosto? Somente os escolhidos pajés sabiam seus rostos, cabia a nós meros curumins criar nossas próprias imaginações daqueles heróis de um tempo antes do mundo existir. Os Lana resolveram isto e hoje sabemos como é Umukomahsü Boreka, o chefe dos Desana.

Alguns podem levantar coro e dizer: quem é Feliciano Lana para dizer o que é e como são as coisas? Engana-se quem pensa que as imagens produzidas era apenas rascunhos da imaginação solitária de um artista, não é tão simples assim. Feliciano Lana é da linhagem Kêhíripõrã, que significa "filho dos desenhos dos sonhos", já nasceu predestinado a ser quem foi. 0 que registrou em tinta sobre papel não eram apenas arte era um profundo conhecimento sobre a cosmologia repassadas por seu tio, grande $\mathrm{Kumu}^{2} \mathrm{e}$ Bayá $^{3}$ dos Kêhíriporã e depois pelas viagens pelas aldeias e conversas com outros mestres indígenas.

A importância de Feliciano Lana para as artes, para a mitologia Desana e para os artistas indígenas contemporâneos posso colocar no mesmo patamar da importância que Michelangelo tem para a história do cristianismo e da arte ocidental. Porém sem um Papa Júlio II no Alto Rio Negro, Feliciano Lana teve o Padre Casimiro Béksta como patrono. Sem acesso ao teto de uma Capela Sistina, Feliciano Lana pintou o teto da Maloca-Universo, onde é possível acompanhar a Gênese, a criação do primeiro ser humano, o dilúvio e incêndio do mundo, a grande Cobra-Canoa. Com ajuda de um padre, Feliciano nos fez acompanhar os primeiros suspiros deste planeta que chamamos de casa, a partir da mitologia Desana, o que é bem irônico, visto que a igreja foi responsável pela grande parte das violências contra os conhecimentos e espiritualidades indígenas. Feliciano também narrava o tempo atual com tintas sobre papel ou tela, esteve em diversas exposições no Brasil e na Europa, pode conhecer o mundo além da aldeia, colocou em seus registros tudo o que aprendia de novo.

A produção de Lana é um banco de dados, conhecimentos mágicos e cotidianos que precisam ser estudados, preservados e compartilhados com todos, principalmente com aqueles que ainda irão nascer.

Feliciano Lana, tem como márter a aldeia de São João Batista, no rio Tiquié, no Distrito de Pari-Cachoeira. No território onde vivem outros vinte e dois povos indígenas. Território que sabe bem sobre a resistência 
de ter que sobreviver a inúmeras epidemias e violências trazidas pelo Estado, assim como todos os povos indígenas deste país, aliás. Infelizmente em 2020 tivemos mais um tempo difícil que não estávamos preparados para enfrentar, longe do Estado e das políticas públicas o interior do Amazonas foi atingido em cheio pelo Covid-19. Infelizmente, assim como outros amigos e amigas o Sr. Feliciano Lana foi levado por este vírus. Se Feliciano fosse Baniwa como eu, diríamos que se transformou em estrela e está agora junto com aqueles que estiveram na Gênese do Universo; como é Desana talvez esteja agora junto a Yebá Buró, talvez escutando com atenção os segredos que não o fora revelado em vida. Talvez esteja registrando o que escuta em papéis e tintas mágicas, que só Yebá Buró conhece.

Os desana perdem, a arte perde, o mundo perde. Toda vez que um mestre, um velho se transforma em estrela do cosmos o mundo perde uma biblioteca de conhecimentos e poesia. Enquanto artista perco um amigo e mestre, um grande exemplo do poder que a arte possui para povos que não tem acesso às camadas mais altas do reconhecimento artístico, mas que mesmo assim mudam completamente o mundo de muitas pessoas, como mudou transformou o meu.

Enquanto artista e indígena, meu dever é manter a memória e legado do Sr. Feliciano vivo e presente, para que a poesia e magnitude dele seja conhecido pelo maior número de pessoas. Cuidar da memória para que ela esteja presente nos pensamentos vivos, pois entender o passado é cuidar para que o futuro seja uma boa experiência para os que virão.

Antes do tempo das cores a escuridão dominava, tudo era um grande vazio. Como um pensamento mágico, surgiu sentado em seu kumurõ ${ }^{4}$, empunhando em suas mãos pincéis e tintas, e ele criou pela sua própria vontade a arte. Antes de Feliciano Lana a arte não existia. Antes da arte o mundo não existia. 